\title{
Prognostic impact of intratumoral vascular invasion in non-small cell lung cancer patients
}

Ryo Maeda, ${ }^{1}$ Junji Yoshida, ${ }^{1}$ Genichiro Ishii, ${ }^{2}$ Tomoyuki Hishida, ${ }^{1}$ Mitsuyo Nishimura, ${ }^{1}$ Kanji Nagai ${ }^{1}$

1Department of Thoracic Oncology, National Cancer Center Hospital East, Kashiwa, Chiba, Japan

${ }^{2}$ Department of Pathology, Research Center for Innovative Oncology, National Cancer Center Hospital East, Kashiwa, Chiba, Japan

\section{Correspondence to} Junji Yoshida, Department of Thoracic Oncology, National Cancer Center Hospital East 6-5-1, Kashiwanoha, Kashiwa, Chiba 277-8577, Japan; jyoshida@east.ncc.go.jp

Received 3 May 2010 Accepted 8 September 2010 Published Online First 22 October 2010

\section{ABSTRACT}

Objective Intratumoral vascular invasion (IVI) in patients with non-small cell lung cancer (NSCLC) has been reported to be a strong independent predictor of recurrence, but it has not been incorporated in the TNM classifications including the latest 7 th edition. The purpose of this study was to evaluate its significance as a risk factor for recurrence.

Methods Between July 1992 and December 2006, 2295 consecutive patients with pathological T1-4NO-2 NSCLC underwent complete resection with systematic lymph node dissection at the National Cancer Center Hospital East. The recurrence-free proportion was estimated using the Kaplan-Meier method and differences were determined by the log rank test. Cox proportional hazard ratios were used to identify independent risk factors for recurrence.

Results The proportion of recurrence-free patients at 5 years was $85.0 \%$ for patients without IVI and $51.5 \%$ for patients with IVI $(\mathrm{p}<0.001)$. On multivariate analyses, IVI proved to be an independently statistically significant risk factor for recurrence (HR 1.866, $p<0.001)$. The recurrencefree proportion of patients with IVI was significantly lower than for patients without IVI in T1a (93.1\% vs $69.3 \%$, $\mathrm{p}<0.001)$, T1b (89.7\% vs $62.7 \%, \mathrm{p}<0.001)$, T2a (78.4\% vs $53.0 \%, p<0.001), \mathrm{T} 2 \mathrm{~b}(70.5 \%$ vs $46.4 \%, \mathrm{p}=0.021)$ and $\mathrm{T} 3$ (53.1\% vs $37.4 \%, p=0.031$ ) subgroups.

Conclusions in resected patients with $\mathrm{T} 1-4 \mathrm{NO}-2$ NSCLC, IVI was an independently significant risk factor for recurrence. IVI should be examined and its data collected to be considered for the next revision of the TNM staging system.

\section{INTRODUCTION}

Intratumoral vascular invasion (IVI) in patients with non-small cell lung cancer (NSCLC) has been reported to be a strong independent predictor of
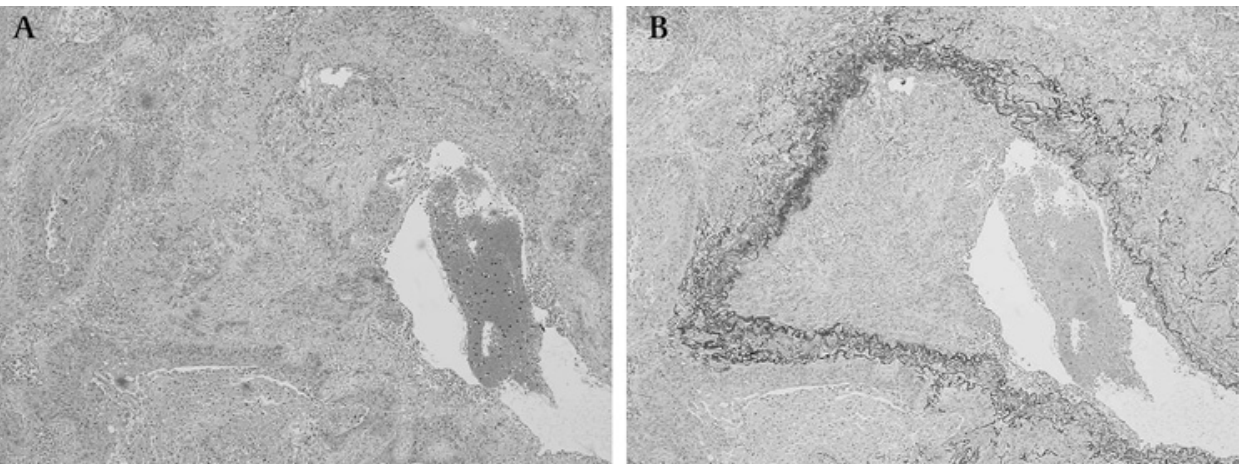

recurrence in most studies that included this factor in their analyses, ${ }^{1-5}$ but it has not been incorporated in the TNM classifications including the latest 7 th edition. ${ }^{6}$

We reviewed a large series of consecutive patients with T1-4N0-2 NSCLC who underwent surgical resection at our hospital. The purpose of this study was to evaluate the significance of IVI as a risk factor for recurrence.

\section{METHODS \\ Patients}

A total of 2359 consecutive patients with pathological T1-4N0-2 NSCLC underwent complete resection with systematic lymph node dissection from July 1992 to December 2006 at the National Cancer Center Hospital East. Complete resection was defined as cancer-free surgical margins both macroscopically and microscopically. Among these patients, 64 were excluded because of preoperative chemotherapy or radiation therapy or both $(n=32)$, or because of low-grade malignant histologies $(\mathrm{n}=32)$ including carcinoids, mucoepidermoid carcinomas and adenoid cystic carcinomas. The remaining 2295 patients were the subjects of this study.

\section{Pathological evaluation}

All surgical specimens were fixed with $10 \%$ formalin and embedded in paraffin. The tumours were cut at approximately $5 \mathrm{~mm}$ intervals and serial $4 \mu \mathrm{m}$ sections were stained using the $\mathrm{H} \& \mathrm{E}$ method. Histological type was determined according to the WHO classification, ${ }^{7}$ and the histological grade was diagnosed and categorised into well and moderately/poorly differentiated carcinoma according to the degree of structural and cytological atypia. Disease stages were based on the TNM Classification for Lung and Pleural Tumours

Figure 1 Intratumoral vascular invasion in a Victoria blue van Gieson (VvG)-stained section of non-small cell lung cancer. Intratumoral vascular invasion within a tumour nest with (A) H\&E staining and (B) VvG staining. 
Table 1 Initial site of failure in patients with recurrence

\begin{tabular}{|c|c|c|c|c|c|c|}
\hline \multirow[b]{2}{*}{ Characteristic } & & \multirow{2}{*}{$\begin{array}{l}\text { No. of } \\
\text { patients } \\
\text { (\%) }\end{array}$} & \multirow{2}{*}{$\begin{array}{l}\text { No. of } \\
\text { recurrences } \\
\text { (\%) }\end{array}$} & \multicolumn{2}{|c|}{$\begin{array}{l}\text { Initial site of } \\
\text { recurrence }\end{array}$} & \multirow[b]{2}{*}{$\begin{array}{l}\mathbf{p} \\
\text { Value } †\end{array}$} \\
\hline & & & & $\begin{array}{l}\text { Local } \\
\text { recurrence }\end{array}$ & $\begin{array}{l}\text { Distant } \\
\text { recurrence }\end{array}$ & \\
\hline Overall & & 2295 & 616 & 204 & 412 & \\
\hline \multirow{2}{*}{$\begin{array}{l}\text { Intratumoral } \\
\text { vascular } \\
\text { invasion }\end{array}$} & Absent & $\begin{array}{l}1151 \\
(50)\end{array}$ & $142(12)$ & $63(44)$ & $79(56)$ & \multirow[t]{2}{*}{$0.002^{*}$} \\
\hline & Present & $\begin{array}{l}1144 \\
(50)\end{array}$ & 474 (41) & $141(30)$ & $333(70)$ & \\
\hline
\end{tabular}

*Indicates significance.

$+\chi^{2}$ test.

of the International Union Against Cancer, 7th edition. ${ }^{6}$ IVI and visceral pleural invasion (VPI) were evaluated by $\mathrm{H} \& \mathrm{E}$ and elastin (Victoria blue-van Gieson) stainings. The presence of IVI was determined by identifying conspicuous clusters of intravascular cancer cells surrounded by an elastic layer (figure 1A, B). Pathological evaluation was reviewed for consistency by a single pathologist (GI) and confirmed for reproducibility by one or more other pathologists. These pathologists were blinded to the clinical outcome.

\section{Patient follow-up}

Patients were examined at 3-monthly intervals for the first 2 years and at 6-monthly intervals thereafter on an outpatient basis. The follow-up evaluation included physical examination, chest radiography and blood examination including that of pertinent tumour markers. Further evaluations including CT scans of the chest and abdomen, brain MRI and bone scintigraphy were performed on the detection of any symptoms or signs of recurrence. Since 2004, integrated positron emission tomography and CT have also been performed when appropriate.

Recurrent NSCLC was diagnosed by physical examination and diagnostic imaging of lesions consistent with recurrent lung cancer. Histological confirmation of the diagnosis was made when clinically feasible. The date of recurrence was defined as the date of histological proof or, in cases diagnosed based upon clinicoradiological findings, the date of identification by

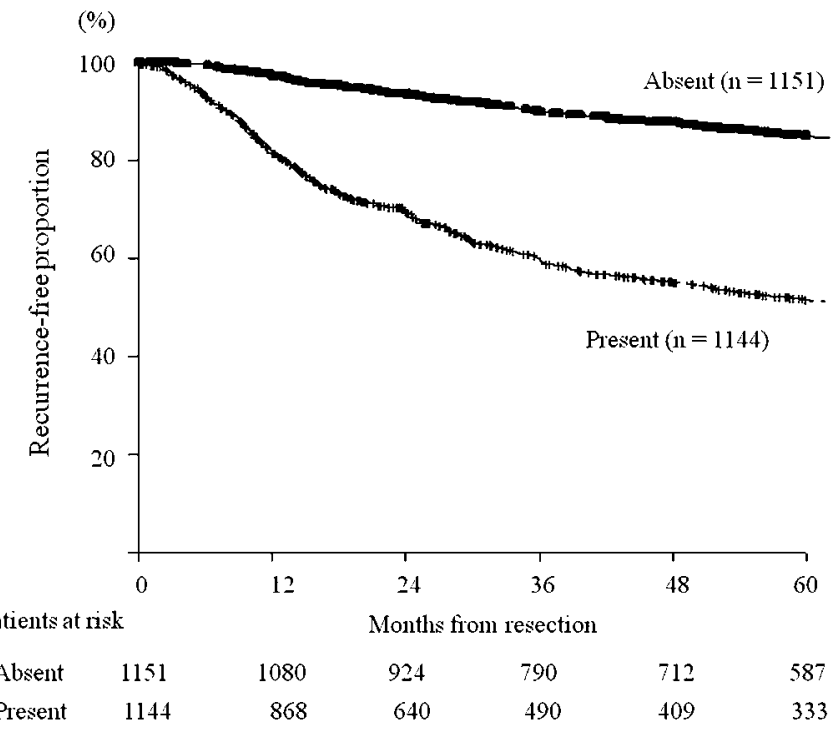

Figure 2 Recurrence-free proportion according to intratumoral vascular invasion in all patients. a physician. In patients with recurrent lesions diagnosed simultaneously at multiple sites, the site of the main clinical interest was recorded.

\section{Clinicopathological information}

We reviewed the medical records of each patient for clinicopathological information including age (dichotomised at the median age of 65 years), gender, smoking history (non- or eversmoker), preoperative ratio of forced expiratory volume in $1 \mathrm{~s}$ to forced vital capacity ( $\mathrm{FEV}_{1} / \mathrm{FVC}$ ratio, $\geq 70 \%$ or $<70 \%$ ), preoperative serum carcinoembryonic antigen (CEA) level (cut-off at the normal upper limit of $5 \mathrm{ng} / \mathrm{ml}$ ), diameter of the tumour on the resected specimens $(\leq 3 \mathrm{~cm}$ or $>3 \mathrm{~cm}$ ), histological differentiation (well differentiated or moderately/poorly differentiated), IVI (presence or absence), lymphatic permeation (presence or absence), VPI (as defined in the TNM classification 7 th

Table 2 Recurrence-free proportion and clinicopathological characteristics of the entire cohort

\begin{tabular}{|c|c|c|c|c|}
\hline Characteristic & & $\begin{array}{l}\text { No. of } \\
\text { patients } \\
(\%)\end{array}$ & $\begin{array}{l}\text { Recurrence- } \\
\text { free proportion } \\
\text { at } 5 \text { years }(\%)\end{array}$ & $\begin{array}{l}\text { Univariate } \\
\text { p value } \dagger\end{array}$ \\
\hline \multicolumn{5}{|l|}{ Overall } \\
\hline \multirow[t]{2}{*}{ Age (years) } & $\leq 65$ & $1149(50)$ & 69.2 & 0.388 \\
\hline & $>65$ & $1146(50)$ & 67.9 & \\
\hline \multirow[t]{2}{*}{ Gender } & Women & $889(38)$ & 70.5 & $0.049^{*}$ \\
\hline & Men & $1406(62)$ & 67.4 & \\
\hline \multirow[t]{2}{*}{ Smoking habits } & Non-smoker & $790(34)$ & 71.2 & $0.008^{*}$ \\
\hline & Ever smoker & $1505(66)$ & 67.2 & \\
\hline \multirow[t]{3}{*}{$\mathrm{FEV}_{1} / \mathrm{FVC}(\%)$} & $\geq 70$ & $1726(75)$ & 69.3 & $0.038 *$ \\
\hline & $<70$ & $559(24)$ & 65.9 & \\
\hline & Not examined & 10 & & \\
\hline \multirow[t]{3}{*}{ CEA } & $\begin{array}{l}\text { Within normal } \\
\text { range }\end{array}$ & $1441(63)$ & 72 & $<0.001^{*}$ \\
\hline & Elevated & 851 (37) & 62.6 & \\
\hline & Not examined & 3 & & \\
\hline \multirow[t]{2}{*}{ Tumour size $(\mathrm{cm})$} & $\leq 3.0$ & $1239(54)$ & 79.5 & $<0.001^{*}$ \\
\hline & $>3.0$ & $1056(46)$ & 55.3 & \\
\hline \multirow[t]{2}{*}{ Histological type } & Adenocarcinoma & $1546(67)$ & 69.8 & $0.009 *$ \\
\hline & Non-adenocarcinoma & $749(33)$ & 66.1 & \\
\hline \multirow{2}{*}{$\begin{array}{l}\text { Histological } \\
\text { differentiation }\end{array}$} & Well differentiated & $628(27)$ & 86.7 & $<0.001^{*}$ \\
\hline & $\begin{array}{l}\text { Moderately/poorly } \\
\text { differentiated }\end{array}$ & $1667(73)$ & 61 & \\
\hline \multirow{2}{*}{$\begin{array}{l}\text { Lymphatic } \\
\text { permeation }\end{array}$} & Absent & $1595(69)$ & 77.7 & $<0.001^{*}$ \\
\hline & Present & $700(31)$ & 49.1 & \\
\hline \multirow{2}{*}{$\begin{array}{l}\text { Intratumoral } \\
\text { vascular invasion }\end{array}$} & Absent & $1151(50)$ & 85 & $<0.001^{*}$ \\
\hline & Present & $1144(50)$ & 51.5 & \\
\hline \multirow{2}{*}{$\begin{array}{l}\text { Visceral pleural } \\
\text { invasion }\end{array}$} & Absent & $1537(67)$ & 77.9 & $<0.001^{*}$ \\
\hline & Present & $758(33)$ & 48.6 & \\
\hline \multirow[t]{2}{*}{$\mathrm{N}$ status } & NO & $1640(71)$ & 80.7 & $<0.001^{*}$ \\
\hline & $\mathrm{N} 1$ or $\mathrm{N} 2$ & $655(29)$ & 36.8 & \\
\hline
\end{tabular}

*Indicates significance.

†Log rank test.

CEA, preoperative serum carcinoembryonic antigen level (normal upper limit $5 \mathrm{ng} / \mathrm{ml}^{\text {); }} \mathrm{FEV}_{1} /$ $\mathrm{FVC}$, forced expiratory volume in $1 \mathrm{~s}$ to forced vital capacity ratio. 
edition ${ }^{6}$; presence or absence), lymph node metastasis (N0 or $\mathrm{N} 1 / \mathrm{N} 2$ ) and pattern of failure.

\section{Statistical analysis}

Differences in categorical outcomes were evaluated by the $\chi^{2}$ test. The length of overall survival rate was calculated in months from the date of resection to the date of death from any cause or last follow-up. The length of the recurrence-free period was calculated in months from the date of resection to the date of the first recurrence or last follow-up. For calculation of the recurrence-free proportion, patients who died without recurrence or who were known to have no recurrence at the date of last contact were censored. All cumulative survival rates or recurrence-free proportions were estimated using the Kaplan-Meier method, and differences in variables were evaluated using the log rank test. Cox proportional hazards multivariate models were used to identify independent predictors. A backward elimination stepwise procedure was used to determine independent predictors. All variables were initially entered into a backward stepwise analysis using $p$ values of 0.10 for entry and 0.05 for removal in each model. Adjusted HRs with 95\% CIs were calculated for each statistically significant variable from the final stepwise model. For comparison, unadjusted HRs with $95 \%$ CIs were calculated for each candidate variable using univariate
Cox analyses to assess the impact of the adjustment. To examine whether the IVI status in addition to the current TNM system would improve the prediction of recurrence more precisely than the current TNM system, subgroup analyses stratified by the current T classification and IVI status were performed. We used the Kaplan-Meier method to plot the recurrence-free proportion curves of subjects stratified by the $\mathrm{T}$ classification and IVI status. Log rank tests were used to compare the recurrencefree proportion among the strata and to determine how to incorporate IVI into the current T classification. To examine the impact of IVI on early stage NSCLC, only patients with stage I NSCLC were similarly analysed. To compare the impact of IVI on patients with stage I NSCLC with T1 or T2 tumours according to the revised WHO classification, subgroup analyses stratified by IVI status and the revised T classification (T1 or T2) in patients with stage I NSCLC were also performed.

The significance level was set at $<0.05$. The analyses were performed using statistical software SPSS 11.0 and GraphPad Prism Version 5.02

\section{RESULTS}

The median follow-up period was 55 months (range 1-162 months). The 5 -year overall survival rate was $67.7 \%$. In patients

Table 3 Univariate and multivariable analysis of risk factors for recurrence in the entire cohort

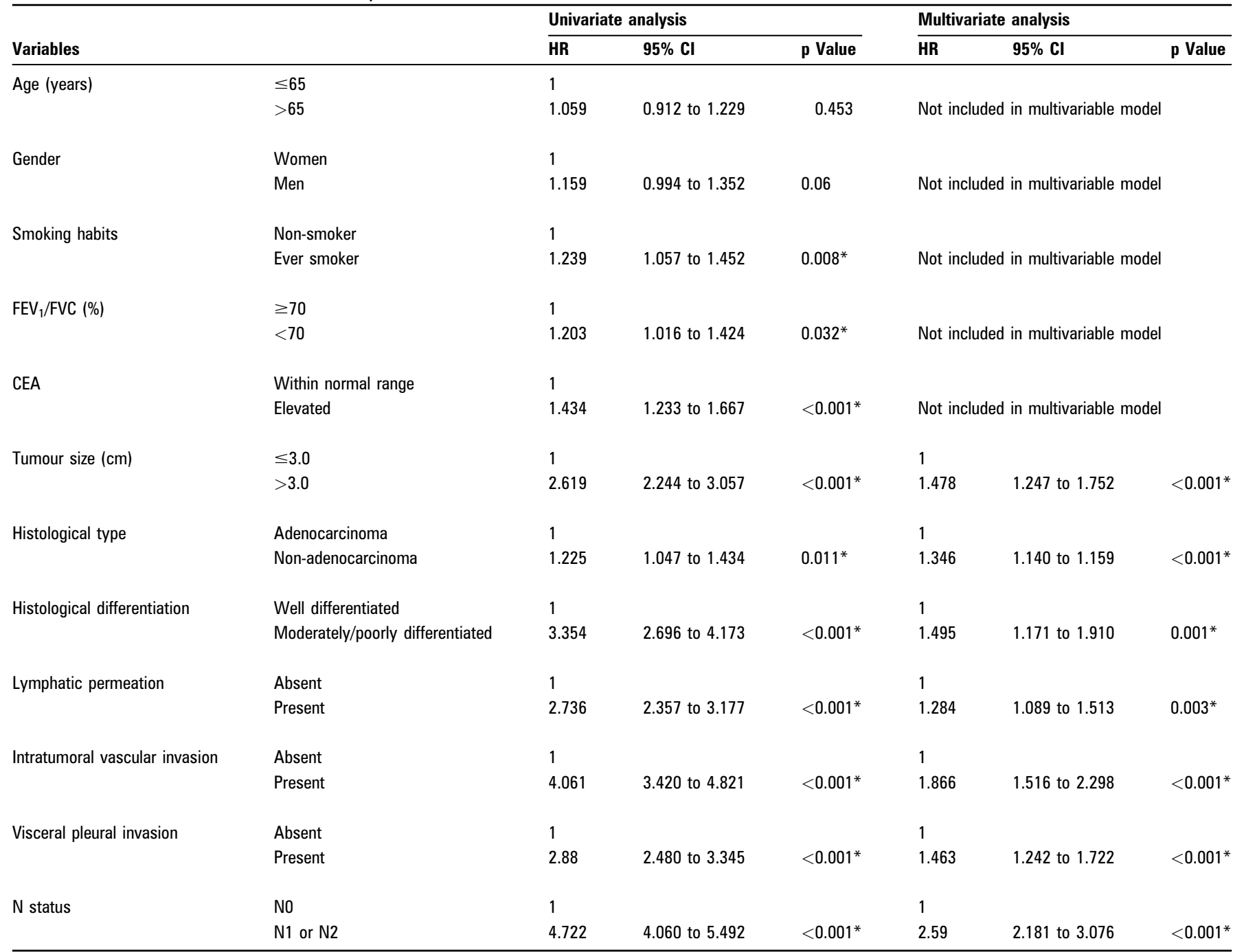


without IVI the 5-year overall survival rate was $83.8 \%$, which was statistically significantly higher than for patients with IVI $(51.7 \%$; $\mathrm{p}<0.001)$.

By 5 years after resection, 616 (26.8\%) had developed recurrence. Recurrence was locoregional in 204 patients and distant in 412 patients. Among patients who developed recurrence, distant metastases were found more often in patients with IVI $(p<0.001$, table 1$)$. The overall recurrence-free proportion was $68.6 \%$ at 5 years after resection. The 5 -year recurrence-free proportion for patients without IVI was $85.0 \%$, which was significantly higher than for patients with IVI $(51.5 \% ; \mathrm{p}<0.001$, figure 2).

The recurrence-free proportions according to clinicopathological factors are shown in table 2. Of the 2295 patients, IVI was found in 1144 (50\%). Gender, smoking habit, FEV 1 /FVC ratio, preoperative serum CEA level, tumour diameter, histology, histological differentiation, lymphatic permeation, IVI, VPI and $\mathrm{N}$ status were statistically significant factors identified by

Table 4 Recurrence-free proportion and clinicopathological characteristics of patients with stage I non-small cell lung cancer

\begin{tabular}{|c|c|c|c|c|}
\hline Characteristic & & $\begin{array}{l}\text { No. of } \\
\text { patients } \\
(\%)\end{array}$ & $\begin{array}{l}\text { Recurrence- } \\
\text { free proportion } \\
\text { at } 5 \text { years }(\%)\end{array}$ & $\begin{array}{l}\text { Univariate } \\
\text { p value } \dagger\end{array}$ \\
\hline Overall & & 1485 & 83.4 & \\
\hline \multirow[t]{2}{*}{ Age (years) } & $\leq 65$ & $722(49)$ & 86.8 & $0.001 *$ \\
\hline & $>65$ & $763(51)$ & 80 & \\
\hline \multirow[t]{2}{*}{ Gender } & Women & $608(41)$ & 87 & $<0.001^{*}$ \\
\hline & Men & $877(59)$ & 80.8 & \\
\hline \multirow[t]{2}{*}{ Smoking habits } & Non-smoker & $546(37)$ & 88.1 & $<0.001^{*}$ \\
\hline & Ever smoker & $939(63)$ & 80.5 & \\
\hline \multirow[t]{3}{*}{$\mathrm{FEV}_{1} / \mathrm{FVC}(\%)$} & $\geq 70$ & $1137(77)$ & 85 & $<0.001^{*}$ \\
\hline & $<70$ & $339(23)$ & 77.4 & \\
\hline & Not examined & 9 & & \\
\hline \multirow[t]{3}{*}{ CEA } & $\begin{array}{l}\text { Within normal } \\
\text { range }\end{array}$ & $995(67)$ & 85.7 & $<0.001^{*}$ \\
\hline & Elevated & $488(33)$ & 78.6 & \\
\hline & Not examined & 2 & & \\
\hline \multirow[t]{2}{*}{ Tumour size $(\mathrm{cm})$} & $\leq 3.0$ & $1001(67)$ & 87.9 & $<0.001^{*}$ \\
\hline & $>3.0$ & $484(33)$ & 78.6 & \\
\hline \multirow[t]{2}{*}{ Histological type } & Adenocarcinoma & $1079(73)$ & 85.5 & $<0.001 *$ \\
\hline & Non-adenocarcinoma & $406(27)$ & 77.6 & \\
\hline \multirow{2}{*}{$\begin{array}{l}\text { Histological } \\
\text { differentiation }\end{array}$} & Well differentiated & $552(37)$ & 93.1 & $<0.001^{*}$ \\
\hline & $\begin{array}{l}\text { Moderately/poorly } \\
\text { differentiated }\end{array}$ & $933(63)$ & 77 & \\
\hline \multirow{2}{*}{$\begin{array}{l}\text { Lymphatic } \\
\text { permeation }\end{array}$} & Absent & $1217(82)$ & 86.3 & $<0.001^{*}$ \\
\hline & Present & $268(18)$ & 71.9 & \\
\hline \multirow{2}{*}{$\begin{array}{l}\text { Intratumoral } \\
\text { vascular invasion }\end{array}$} & Absent & $975(66)$ & 91.9 & $<0.001^{*}$ \\
\hline & Present & $510(34)$ & 67.3 & \\
\hline \multirow{2}{*}{$\begin{array}{l}\text { Visceral pleural } \\
\text { invasion }\end{array}$} & Absent & $1168(79)$ & 87.8 & $<0.001^{*}$ \\
\hline & Present & $317(21)$ & 66.6 & \\
\hline
\end{tabular}

*Indicates significance.

†Log rank test.

CEA, preoperative serum carcinoembryonic antigen level (normal upper limit $5 \mathrm{ng} / \mathrm{ml}^{\text {); }} \mathrm{FEV}_{1}$ /

FVC, forced expiratory volume in $1 \mathrm{~s}$ to forced vital capacity ratio. univariate analysis (log rank test, table 2). On multivariate analysis with the Cox regression model, larger tumour size, non-adenocarcinoma histology, poor/moderate histological differentiation, presence of lymphatic permeation, IVI, VPI and lymph node metastasis were shown to be statistically significant independent predictors for recurrence (table 3).

To examine the impact of IVI on patients with early stage N0 NSCLC, only patients in stage I were analysed. Of these 1485 patients, 546 (37\%) were non-smokers and IVI was found in 510 (34\%). Univariate analysis (log rank test) identified 12 statistically significant predictors for recurrence: age, gender, smoking habit, $\mathrm{FEV}_{1} / \mathrm{FVC}$ ratio, preoperative serum CEA level, tumour diameter, histology, histological differentiation, lymphatic permeation, IVI, VPI and $\mathrm{N}$ status (table 4). On multivariate analysis with the Cox regression model, older age, larger tumour size, poor/moderate histological differentiation, presence of lymphatic permeation, IVI and VPI remained as statistically significant independent predictors for recurrence (table 5). Subgroup analysis of patients with stage I disease stratified by $\mathrm{T}$ factor (T1 or T2) and IVI (presence or absence) revealed 5-year recurrence-free proportions of $94.6 \%, 74.5 \%, 85.6 \%$ and $63.9 \%$ for $\mathrm{T} 1 / \mathrm{IVI}(-)$, T1/IVI(+), T2/IVI(-) and T2/IVI(+) patients, respectively (figure 3$)$. The difference in the recurrence-free proportion was statistically significant between the T1/IVI(+) and T2/IVI $(-)$ subgroups $(p=0.016)$.

We analysed the recurrence-free proportion of patients stratified by T subgroup (T1a, T1b, T2a, T2b and T3) and IVI status (presence or absence) (table 6). There were 13 T4N0-2 patients in the study cohort, all of whom had IVI. There was a statistically significant difference in the recurrence-free proportion between patients with or without IVI in $T 1 / 2 / 3$ subgroups (table 6). Compared with these subgroups, a significantly lower recurrence-free proportion was observed for T3/IVI(+) and T4 patients. Table 7 shows the $p$ values of survival difference evaluated by log rank test. The best recurrence-free proportion was observed in the patients with $\mathrm{T1a} / \mathrm{IVI}(-)$ (group A), followed by $\mathrm{T} 1 \mathrm{~b} / \mathrm{IVI}(-)$ (group C), but there was no statistically significant difference between the groups. In comparison, a similar statistically significantly lower recurrence-free proportion was observed among patients with $\mathrm{T} 1 \mathrm{a} / \mathrm{IVI}(+)$ (group B), $\mathrm{T} 1 \mathrm{~b} / \mathrm{IVI}(+)$ (group D), T2a/IVI(-) (group E) and T2b/IVI(-) (group G). A similar low recurrence-free proportion was seen in patients with T2a/IVI $(+$ ) (group F), T2b/IVI(+) (group H) and T3/IVI(-) (group I). The worst survival was observed in patients with T3/IVI(+) (group J) and T4 (group K).

\section{DISCUSSION}

Several clinicopathological prognostic factors for NSCLC have been identified, including lymphatic permeation, ${ }^{8}$ degree of histological differentiation, ${ }^{9}{ }^{10}$ serum CEA level, ${ }^{11}{ }^{12}$ VPI $^{13}$ and lymph node metastasis, in addition to IVI. ${ }^{1-5}$ Multivariate analyses showed that IVI was an independently statistically significant predictor for recurrence in patients with T1-4N0-2 NSCLC and was the most powerful recurrence predictor (HR 1.866) next to lymph node metastasis (HR 2.590).

On examining only the stage I patients, we identified six independently statistically significant predictors for recurrence by multivariate analyses (table 5); IVI was the most powerful recurrence predictor (HR 2.487) in these patients. Our result is compatible with previous reports ${ }^{1-5}$ and indicates that the presence of IVI has a strong impact on clinical outcome in patients with stage I NSCLC. Subgroup analysis stratified by $\mathrm{T}$ factor (T1 or T2) and IVI (presence or absence) in patients with 
Table 5 Univariate and multivariable analysis of poor prognostic factors and risk factors for recurrence in patients with stage I non-small cell lung cancer

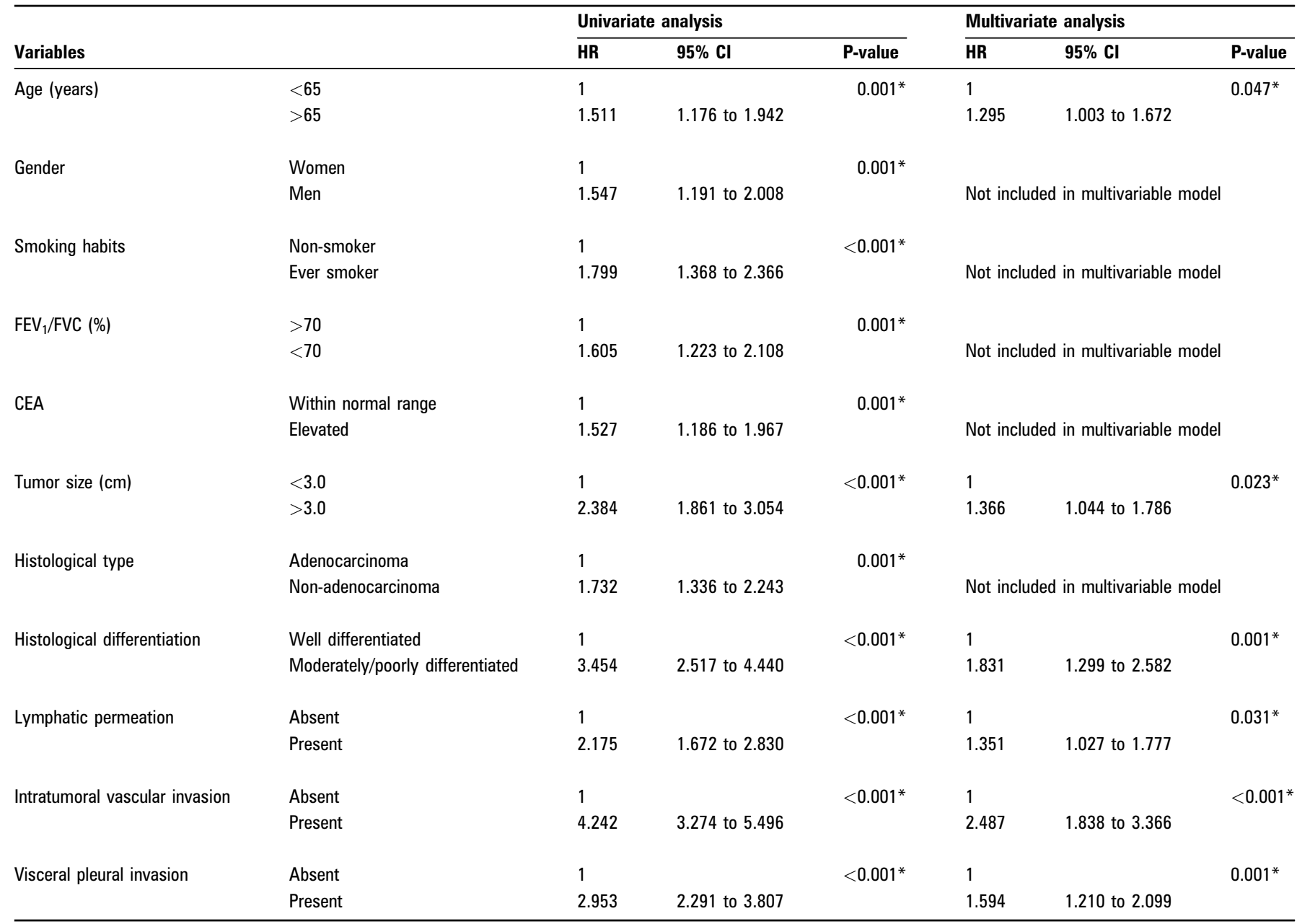

*Indicates significance.

CEA, preoperative serum carcinoembryonic antigen level (normal upper limit $5 \mathrm{ng} / \mathrm{ml}$ ); FEV $/$ FVC, forced expiratory volume in $1 \mathrm{~s}$ to forced vital capacity ratio; HR, HR for recurrence.

stage I disease showed that the 5-year recurrence-free proportion was significantly lower in patients with a T1/IVI(+) tumour than in those with a T2/IVI $(-)$ tumour $(p=0.016)$. Recent

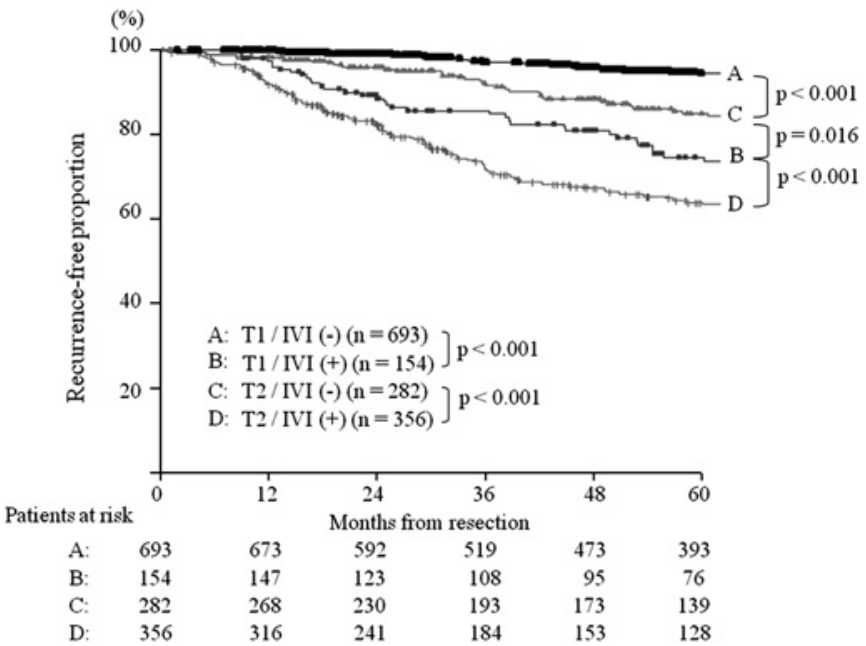

Figure 3 Recurrence-free proportion of patients with stage I disease stratified by T classification (T1 or T2) and intratumoral vascular invasion (IVI). randomised controlled trials have shown survival benefit from platinum-based adjuvant chemotherapy in patients with stage II or higher NSCLC. ${ }^{14}{ }^{15}$ For patients with stage IB adenocarcinoma, based on a large adjuvant trial and meta-analyses on oral uracil-tegafur (UFT), UFT adjuvant chemotherapy is recommended as the standard treatment in Japan. ${ }^{16}$ Although surgery alone remains the standard treatment for patients with stage IA disease, the seminal prospective study of Kato et al ${ }^{16}$ showed that oral UFT may improve survival in patients with stage IA disease. Patients with stage IA NSCLC with IVI may therefore be good candidates for UFT adjuvant chemotherapy.

The reported detection rates of IVI in pathological stage I without any elastic stains were $11-16 \% .^{1} 17$ In contrast, those with elastic stains ranged from $27 \%$ to $56 \%^{2} 41819$ and were apparently higher than those without. We uniformly used H\&E and Victoria blue-van Gieson stains on all tumours. The detection rate was $34.3 \%(510 / 1485)$ for patients with pathological stage I, which was similar to previous studies. These findings suggest that elastic staining helps pathologists to identify IVI more accurately. In the latest 7 th edition of the TNM classification, VPI is clearly defined and T1 tumours remain to be upgraded to T2 when the visceral pleura elastic layer is invaded. ${ }^{6}$ Elastic staining is also helpful in identifying VPI. ${ }^{13} 20 \mathrm{We}$ therefore recommend the routine use of elastic stains in pathological evaluations of lung cancer, not only for VPI 
Table 6 Recurrence-free proportion of patients stratified by T classification and IVI status in the entire cohort

\begin{tabular}{|c|c|c|c|c|c|c|c|}
\hline $\begin{array}{l}\text { T } \\
\text { classification }\end{array}$ & Patients (\%) & $\begin{array}{l}\text { Recurrence-free } \\
\text { proportion at } 5 \text { years (\%) }\end{array}$ & Group & $\begin{array}{l}\text { IVI } \\
\text { status }\end{array}$ & $\begin{array}{l}\text { Patients } \\
\text { (\%) }\end{array}$ & $\begin{array}{l}\text { Recurrence-free } \\
\text { proportion at } 5 \text { years }(\%)\end{array}$ & $\begin{array}{l}\text { Univariate } p \text { value } \\
\text { by log rank test }\end{array}$ \\
\hline \multirow[t]{2}{*}{ T1a } & $515(23)$ & 90 & A & $(-)$ & 425 (19) & 93.1 & $<0.001^{*} \dagger$ \\
\hline & & & B & $(+)$ & $90(4)$ & 69.3 & \\
\hline $\mathrm{T} 1 \mathrm{~b}$ & & & D & $(+)$ & $136(6)$ & 62.7 & \\
\hline \multirow[t]{2}{*}{ T2a } & $825(36)$ & 62.4 & $E$ & $(-)$ & $302(13)$ & 78.4 & $<0.001^{*} \dagger$ \\
\hline & & & $\mathrm{F}$ & $(+)$ & $523(23)$ & 53 & \\
\hline \multirow[t]{2}{*}{ T3 } & 336 (14) & 41.2 & 1 & $(-1)$ & $75(3)$ & 53.1 & $0.031^{*} \dagger$ \\
\hline & & & $J$ & $(+)$ & $261(11)$ & 37.4 & \\
\hline $\mathrm{T} 4$ & $13(6)$ & 34.2 & K & & $13(6)$ & 34.2 & $0.215 \ddagger$ \\
\hline Total & 2295 & 68.6 & & & & & \\
\hline
\end{tabular}

T classification based on the 7th edition of the TNM Classification for Lung and Pleural Tumours.

*Indicates significance.

tp value for each T subclassification with or without IVI.

$\neq \mathrm{p}$ value vs group $\mathrm{J}$.

IVI, intratumoral vascular invasion.

Table 7 Univariate analysis of recurrence-free proportion of patients stratified by T classification and IVI status

\begin{tabular}{|c|c|c|c|c|c|c|c|}
\hline \multirow{2}{*}{$\frac{\text { Group }}{\mathrm{A}}$} & \multirow{2}{*}{$\begin{array}{l}\begin{array}{l}\mathbf{T} \\
\text { classification }\end{array} \\
\text { T1a }\end{array}$} & \multirow{2}{*}{$\begin{array}{l}\begin{array}{l}\text { IVI } \\
\text { status }\end{array} \\
(-)\end{array}$} & \multirow{2}{*}{$\begin{array}{l}\begin{array}{l}\text { Patients } \\
(\%)\end{array} \\
425(19)\end{array}$} & \multirow{3}{*}{$\begin{array}{l}\begin{array}{l}\text { Recurrence-free } \\
\text { proportion at } \mathbf{5} \text { years (\%) }\end{array} \\
93.1\end{array}$} & \multicolumn{3}{|c|}{$\mathrm{p}$ Value by log rank test } \\
\hline & & & & & vs & Group C & 0.244 \\
\hline & & & & & & Group $\mathrm{E}$ & $<0.001^{*}$ \\
\hline C & T1b & $(-)$ & $312(14)$ & 89.7 & vs & Group E & $<0.001^{*}$ \\
\hline \multirow[t]{3}{*}{$\mathrm{E}$} & $\mathrm{T} 2 \mathrm{a}$ & $(-1)$ & $302(13)$ & 78.4 & vs & Group G & 0.224 \\
\hline & & & & & & Group B & $0.018^{*}$ \\
\hline & & & & & & Group D & $<0.001^{*}$ \\
\hline \multirow[t]{3}{*}{ G } & $\mathrm{T} 2 \mathrm{~b}$ & $(-)$ & $37(16)$ & 70.5 & vs & Group B & 0.751 \\
\hline & & & & & vs & Group D & 0.485 \\
\hline & & & & & vs & Group I & 0.071 \\
\hline \multirow[t]{2}{*}{ B } & T1a & $(+)$ & $90(4)$ & 69.3 & vs & Group D & 0.578 \\
\hline & & & & & vs & Group I & $0.047^{*}$ \\
\hline \multirow[t]{2}{*}{$D$} & $\mathrm{~T} 1 \mathrm{~b}$ & $(+)$ & $136(6)$ & 62.7 & vs & Group I & 0.08 \\
\hline & & & & & vs & Group F & 0.052 \\
\hline \multirow[t]{3}{*}{ I } & T3 & $(-)$ & $75(3)$ & 53.1 & vs & Group F & 0.64 \\
\hline & & & & & vs & Group H & 0.449 \\
\hline & & & & & vs & Group J & $0.031^{*}$ \\
\hline $\mathrm{F}$ & T2a & $(+)$ & $523(23)$ & 53 & vs & Group H & 0.093 \\
\hline \multirow[t]{2}{*}{$\mathrm{H}$} & $\mathrm{T} 2 \mathrm{~b}$ & $(+)$ & $121(5)$ & 46.4 & vs & Group J & 0.069 \\
\hline & & & & & vs & Group K & 0.072 \\
\hline J & T3 & $(+)$ & 261 (11) & 37.4 & vs & Group K & 0.215 \\
\hline K & T4 & & $13(6)$ & 34.2 & & & \\
\hline
\end{tabular}

*Indicates significance.

$\mathrm{IVI}$, intratumoral vascular invasion.

Table 8 Proposal on incorporating IVI into T classification

\begin{tabular}{|c|c|c|c|c|c|c|c|}
\hline Group & $\begin{array}{l}\mathbf{T} \\
\text { classification }\end{array}$ & $\begin{array}{l}\text { IVI } \\
\text { status }\end{array}$ & $\begin{array}{l}\text { Patients } \\
(\%)\end{array}$ & $\begin{array}{l}\text { Recurrence-free } \\
\text { proportion at } 5 \text { years (\%) }\end{array}$ & $\begin{array}{l}\text { Our } \\
\text { proposal }\end{array}$ & $\begin{array}{l}\text { Patients } \\
(\%)\end{array}$ & $\begin{array}{l}\text { Recurrence-free } \\
\text { proportion at } 5 \text { years (\%) }\end{array}$ \\
\hline A & T1a & $(-)$ & 425 (19) & 93.1 & $\mathrm{~T} 1$ & $737(32)$ & 91.7 \\
\hline C & $\mathrm{T} 1 \mathrm{~b}$ & $(-)$ & $312(14)$ & 89.7 & & & \\
\hline$E$ & $\mathrm{~T} 2 \mathrm{a}$ & $(-)$ & 302 (13) & 78.4 & $\mathrm{~T} 2$ & $585(25)$ & 72.6 \\
\hline G & $\mathrm{T} 2 \mathrm{~b}$ & $(-)$ & $37(16)$ & 70.5 & & & \\
\hline B & T1a & $(+)$ & $90(4)$ & 69.3 & & & \\
\hline D & T1b & $(+1$ & $136(6)$ & 62.7 & & & \\
\hline I & T3 & $(-)$ & $75(3)$ & 53.1 & T3 & $719(31)$ & 52.1 \\
\hline $\mathrm{F}$ & T2a & $(+)$ & $523(23)$ & 53 & & & \\
\hline $\mathrm{H}$ & $\mathrm{T} 2 \mathrm{~b}$ & $(+)$ & $121(5)$ & 46.4 & & & \\
\hline$J$ & T3 & $(+)$ & $261(11)$ & 37.4 & T4 & 274 (12) & 37.3 \\
\hline K & T4 & & $13(6)$ & 34.2 & & & \\
\hline
\end{tabular}

IVI, intratumoral vascular invasion. 


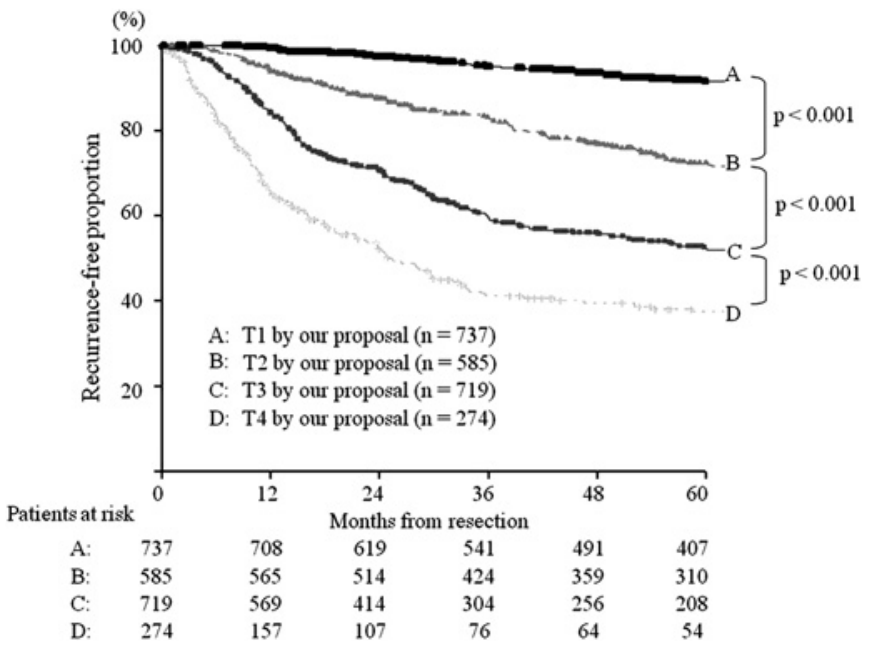

Figure 4 Recurrence-free proportion curves according to our T classification proposal.

determination, as recommended in the TNM classification, but also for IVI determination, especially in patients with stage I NSCLC, to select patients with IVI who might benefit from adjuvant chemotherapy.

Although the 7th edition briefly refers to venous invasion, ${ }^{6}$ IVI has not been incorporated in the TNM classification. In the present study, multivariate analysis showed that IVI (HR 1.866) had a stronger impact on recurrence than VPI (HR 1.463) in the new TNM staging system. In addition, there was a statistically significant difference in the recurrence-free proportion in each $\mathrm{T}$ subgroup (T1a, T1b, T2a, T2b and T3) between patients with or without IVI (table 6). Table 7 suggests that T1a/IVI(+) and $\mathrm{T} 1 \mathrm{~b} / \mathrm{IVI}(+)$ should be upstaged to $\mathrm{T} 2, \mathrm{~T} 2 \mathrm{a} / \mathrm{IVI}(+)$ and $\mathrm{T} 2 \mathrm{~b} /$ $\mathrm{IVI}(+)$ should be upstaged to T3, and T3/IVI(+) should be upstaged to T4. Based on these suggestions, 11 recurrence-free proportions in table 8 appeared to be grouped into four categories, which we have summarised in our proposal in table 8. This simple classification can incorporate the prognostic impact of IVI status into the 7 th edition $\mathrm{T}$ classification reasonably well (figure 4).

However, as shown in table 7 , differences in the recurrencefree proportion between T1b/IVI(+) (group D) and T3/IVI(-) (group I) and between T2b/IVI $(+$ ) (group $\mathrm{H}$ ) and T3/IVI $(+$ ) (group J) were only marginal. In the proposed T2 group, there was a statistically significant difference in the recurrence-free proportion between $\mathrm{T} 2 \mathrm{a} / \mathrm{IVI}(-)$ (group E) and T1a and b/IVI(+) (groups B and D). Our proposal is not complete, but our data clearly indicate that IVI has a very strong prognostic impact comparable with VPI. Therefore, in addition to VPI, IVI should be examined and data collected for the next revision of the TNM staging system to determine how to incorporate IVI into the T classification.

In conclusion, IVI is a strong and independent recurrence risk factor in patients with T1-4N0-2 NSCLC. IVI should be examined with elastic stains and the data collected to be considered for the next revision of the TNM staging system.

Acknowledgements The authors thank Professor J Patrick Barron and Roderick J Turner of the Department of International Medical Communications of Tokyo Medical
University for their review of this manuscript. All work included in the manuscript is performed at National Cancer Center Hospital East, Kashiwa, Chiba, Japan.

\section{Competing interests None.}

Patient consent Obtained.

Ethics approval Data collection and analyses were approved and the need to obtain informed consent from each patient was waived by the institutional review board.

Provenance and peer review Not commissioned; externally peer reviewed.

\section{REFERENCES}

1. Harpole DH Jr, Herndon JE 2nd, Young WG Jr, et al. Stage I nonsmall cell lung cancer. A multivariate analysis of treatment methods and patterns of recurrence. Cancer 1995;76:787-96.

2. Ichinose Y, Yano T, Asoh $\mathrm{H}$, et al. Prognostic factors obtained by a pathologic examination in completely resected non-small-cell lung cancer. An analysis in each pathologic stage. J Thorac Cardiovasc Surg 1995:110:601-5.

3. Yoshida J, Nishimura M, Takahashi K, et al. Conventional clinicopathologic prognostic factors in surgically resected nonsmall cell lung carcinoma. A comparison of prognostic factors for each pathologic TNM stage based on multivariate analyses. Cancer 1999;86:1976-84

4. Suzuki K, Nagai K, Yoshida J, et al. Blood vessel invasion and expression of sialy Lewisx and proliferating cell nuclear antigen in stage I non-small cell lung cancer. Relation to postoperative recurrence. Cancer 1994;73:1177-83.

5. Miyoshi K, Moriyama S, Kunitomo T, et al. Prognostic impact of intratumoral vesse invasion in completely resected pathologic stage I non-small cell lung cancer. J Thorac Cardiovasc Surg 2009;137:429-34.

6. Goldstraw P, Crowley J, Chansky K, et al. The IASLC Lung Cancer Staging Project: proposals for the revision of the TNM stage groupings in the forthcoming (seventh) edition of the TNM classification of malignant tumours. J Thorac Oncol 2007:2:706-14.

7. Travis WD, Brambilla E, Muller-Hermelink HK, et al. World Health Organization Classification of Tumors: Pathology and Genetics of Tumors of the Lung, Pleura, Thymus and Heart. Lyon: IARC Press, 2004.

8. Takise A, Kodama T, Shimosato $Y$, et al. Histopathologic prognostic factors in adenocarcinomas of the peripheral lung less than $2 \mathrm{~cm}$ in diameter. Cancer 1988;61:2083-8

9. Eto $\mathbf{T}$, Suzuki $\mathrm{H}$, Honda A, et al. The changes of the stromal elastotic framework in the growth of peripheral lung adenocarcinomas. Cancer 1996;77:646-56.

10. Fukushima M, Fukuda $Y$, Kawamoto $\mathbf{M}$, et al. Elastosis in lung carcinoma: immunohistochemical, ultrastructural and clinical studies. Pathol Int 2000:50:626-35

11. Takamochi K, Nagai $K$, Suzuki K, et al. Clinical predictors of N2 disease in non-small cell lung cancer. Chest 2000;117:1577-82.

12. Matsuguma H, Nakahara R, Igarashi S, et al. Pathologic stage I non-small cell lung cancer with high levels of preoperative serum carcinoembryonic antigen: clinicopathologic characteristics and prognosis. J Thorac Cardiovasc Surg 2008; 135:44-9.

13. Shimizu K, Yoshida J, Nagai K, et al. Visceral pleural invasion classification in non-small cell lung cancer: a proposal on the basis of outcome assessment. $J$ Thorac Cardiovasc Surg 2004;127:1574-8.

14. Winton T, Livingston R, Johnson D, et al. National Cancer Institute of Canada Clinica Trials Group; National Cancer Institute of the United States Intergroup JBR.10 Tria Investigators. Vinorelbine plus cisplatin vs. observation in resected non-small-cell lung cancer. N Engl J Med 2005:352:2589-97.

15. Arriagada R, Bergman B, Dunant A, et al. International Adjuvant Lung Cancer Trial Collaborative Group. Cisplatin-based adjuvant chemotherapy in patients with completely resected non-small-cell lung cancer. N Engl J Med 2004;350:351-60.

16. Kato H, Ichinose $\mathrm{Y}$, Ohta $\mathrm{M}$, et al. Japan Lung Cancer Research Group on Postsurgical Adjuvant Chemotherapy. A randomized trial of adjuvant chemotherapy with uracil-tegafur for adenocarcinoma of the lung. $N$ Engl J Med 2004;350:1713-21.

17. Poleri C, Morero JL, Nieva B, et al. Risk of recurrence in patients with surgically resected stage I non-small cell lung carcinoma: histopathologic and immunohistochemical analysis. Chest 2003;123:1858-67.

18. Macchiarini $\mathbf{P}$, Fontanini G, Hardin MJ, et al. Blood vessel invasion by tumour cells predicts recurrence in completely resected T1 NO MO non-small-cell lung cancer. J Thorac Cardiovasc Surg 1993;106:80-9.

19. Bréchot JM, Chevret S, Charpentier MC, et al. Blood vessel and lymphatic vesse invasion in resected nonsmall cell lung carcinoma. Correlation with TNM stage and disease free and overall survival. Cancer 1996;78:2111-18.

20. Bunker ML, Raab SS, Landreneau RJ, et al. The diagnosis and significance of visceral pleural invasion in lung carcinoma. Histologic predictors and the role of elastic stains. Am J Clin Pathol 1999:112:777-83. 